\title{
Social aspects of the COVID-19 pandemic in the education system
}

\author{
I. Sh. Mukhametzyanov*
}

Institute for Strategy of Educational Development of the Russian Academy of Education, Zhukovsky str., 16, 105062 Moscow, Russia

\begin{abstract}
The COVID-19 pandemic has altered the life of modern society forever. Not only the economy has changed, but also the person himself and his way of life, his communications. The education system and its role in society have also changed. Analysis of public reviews of recent years, as well as national and international programs aimed at compensation of the social consequences of distance learning. The existing stratification of society is changing from an economic to a digital paradigm because of the pandemic and it is impossible to overcome it within the framework of only separate education system. But the simultaneous digital development of the largest possible group of people - students and their parents, their upbringing and development are only possible within the framework of this system. All the social consequences of distance learning during the 2020 pandemic can best be understood in retrospect. There is no doubt that the decline in the quality of education will lead to significant difficulties in offsetting it. Now we can note a significant increase in the inequality among the population in the new area, the area of access to digital technologies and the digital state.
\end{abstract}

\section{Introduction}

In 2019 and 2020, four billion people worldwide found themselves in a situation of limited social and professional contacts as a result of the COVID-19 pandemic. The world has never experienced such massive restrictions on communications and human rights [1]. Naturally, the restrictions had a profound impact on a person's life, had profound social consequences: both short-term and long-term. Digital and economic inequality, serious changes in mental health, inequality in access to health care, gender inequality, and much more are direct negative social consequences [2]. The Covid-19 pandemic will end sooner or later. But the changes in the life of modern society that were forced to be made in the emergency situation of overcoming the consequences of the pandemic will remain. There will remain social distancing, active collection and use of personal data by state and commercial structures, the usual restriction of freedoms, and so on. The social stratification will continue, and probably will increase, not so much on economic grounds, but based on the level of digital competencies, readiness and possibility of obtaining and developing them.

\footnotetext{
* Corresponding author: ishm@inbox.ru
} 


\section{Methods}

For the purposes of this study, we reviewed the literature of the last year regarding the consequences of mass quarantine during the COVID-19 pandemic in 2020 and the existing approaches in different countries to solving emerging social problems in the field of education.

\section{Discussion}

Undoubtedly, this situation could not but affect the education system. The need for its rapid transformation under the influence of social distancing has made distance learning (DL) in an online format a priority. In the absence of proven technologies and platforms for mass education, training was conducted in an open mode, without any protection of personal data and online communication itself. Hastily prepared applications and platforms for DL have undocumented capabilities to collect commercial information and personal data, the fate of which is extremely vague. These platforms and other technological solutions were not based on the most recognized pedagogical practices, but rather on the most technological practices, which further technologized learning in the absence of choice for the teacher. In fact, training in 2020 was conducted based on the capabilities of adapted or specially designed platforms outside of existing principles of didactics, education and development of students, in fact, it was carried out by teachers but was limited by the framework, which was based on the way technology companies understand learning. Of the video conferencing systems, the most commonly used were Zoom, Skype, Microsoft Teams, and WhatsApp. And these systems are quite secure. But their cost might become a barrier for most educational organizations (EO) [3].

The importance of the protection of personal data within the DL platforms is also highlighted by the fact of a significant deterioration in human rights, especially social ones. This is due to the state of emergency and measures affecting freedom of assembly and freedom of movement. The deterioration of social rights in terms of health, education, work and housing is most typical for groups of people in institutional conditions, the elderly, people with disabilities, migrants, and travelers [4].

The significance of the actual digital transformation of not education, but only learning, is also noted in the final report of UNESCO for 2020, which indicates that these changes have captured 1.5 billion of the world's population ( $90 \%$ of all students) - students at all levels of education [5]. And the main problem areas of learning in the new format include teachers and the quality of their digital competencies, the quality of communication between teachers and students, as well as significant gender inequality.

Considering the quality of DL and the possibility of compensating for gaps in knowledge among students based on UN, UNESCO and UNICEF statistics, it should be noted that according to the analysis of data from the Ministries of Education of 118 countries in the period from May to June 2020, and 149 countries in the period from July to October 2020, the assessment of the level of knowledge of students is not carried out by all countries. The average figure is the loss of 47 full-time school days. Only $86 \%$ of countries reported that students ' learning is fully supervised by teachers, but in developing countries, $25 \%$ of the learning is conducted without the supervision of the teacher and the educational organization. At the same time, $84 \%$ of countries confirmed the introduction of special programs in order to mitigate the losses as the work of the EO is resumed [6]. Conducting comparative studies of the effectiveness of distance learning compared to in-person learning, a number of researchers show a deterioration in the results in natural sciences while the results in reading are maintained, and the degree of loss increases from junior to senior classes. A sample of five million students in grades 3-8 was studied. The worst results were observed in 
mathematics. In the case of ending of DL governments and EO will have to make significant efforts not only to overcome the digital divide of students, but also to develop new approaches and digital educational resources (DER) in a number of subject areas in terms of differentiated approaches to teaching different groups of students and different subjects [7].

The Organization for Economic Cooperation and Development (OECD), together with the Graduate School of Education (Harvard, USA), estimated the impact of school closures on continuity of education as a shortfall of approximately 2 months of offline study. This time was spent on the transition from offline study to distance learning and training teachers and students in regard to online classes, use of TV and radio-programs in education, and elearning. But these two months also have a certain delayed impact, the manifestations of which are still difficult to predict due to the fact that this may be due to the long-term impact of school closures on student performance and obvious difficulties in integrating information and communication technologies into the educational process [8]. Studies have shown that it will take at least 2 years to compensate for losses sustained in 2019-2020, and it is simply impossible to predict further losses if DL is continued. There is a decrease in reading and comprehension skills by $63-68 \%$ and in mathematical skills by $37-50 \%$ in comparison with normal offline education [9]. An additional difficulty is the inability or unwillingness of a number of students, affected by socio-economic difficulties, to attend classes in a remote format. And, according to different countries of the world, their number ranges from $5 \%$ to $13 \%$. But this two-month gap can be quickly compensated for with offline education, although long-term problems will most likely not be solved. These are primarily the digital inequality of students and the high level of learning avoidance during school closures. The OECD (Programme for International Student Assessment-PISA) project is currently developing a special questionnaire module for building a comparative data set and documenting the educational consequences of the crisis in different countries [10]. It is necessary to increase the involvement of students in educational activities during DL, to dynamically track their involvement in it, tracking their attendance, behavior and progress in learning. For these purposes, it is possible to use the SeQoL (Self-Efficacy Questionnaire for Online Learning) questionnaire with proven validity and reliability to identify subgroups of students and to develop support and course activities aimed at students with different profiles of self-efficacy in distance learning. Additionally, SeQoL can be used as a self-assessment tool by online learners [11]. It is also necessary to make more active use of additional incentives in the form of providing technical means of Internet access to those in need of them or organizing safe places for individual or collective access to them. Even with the termination of distance learning and the transition to face-to-face education elements of digital technologies will remain in the learning process, and it will be implemented in a blended format, i.e., the format of using the Internet to accomplish tasks that cannot be performed personally, for example, in the lab, etc. And, if within the framework of professional and vocational education, training can be implemented in an asynchronous format, then in primary and secondary education it is more rational to implement it in the format of synchronous training, since it is based on the effect of the student's presence in a certain social group and his work in it $[12,13]$.

Within the EU, there is an action plan for the digital transformation of education (2021 2027), which focuses on adapting existing education to a digital format; developing the infrastructure for informatization of education; effective planning and development of digital potential; developing digital competencies of teachers; creating common principles for the production of digital educational content and secure platforms focused on the confidentiality of data of participants in the learning process [14]. At the heart of this plan is the understanding that a significant part of the EU population does not have access to computers and broadband Internet outside of the EO, as a result of which one in five young people does not reach even a basic level of digital competence. $60 \%$ of students before the 2020 pandemic 
did not have any DL skills and every second student at the end of 2020 would like to achieve a higher level of digital competencies [15]. One of the participants in the implementation of the program is the European Network for Distance and E-Learning (EDEN), integrated with the Erasmus program, focused on promoting the elements of the digital educational technologies (DET) in relation to distance learning (http://www.eden-online.org/)

The almost simultaneous transition from full-time education within the framework of an educational organization to distance education revealed another common problem, the problem of creating DET adequate to the goals of education and ways of presenting them to students within the framework of digital communication. Their development and implementation was carried out simultaneously with the training process and did not have an adequate experimental assessment. Activities to support teachers in relation to the DER in the format of webinars or online conferences, in the format of broadcasting the experience of long-standing online universities did not take into account the teacher's workload and the complexity of transforming the practice of technical, vocational and additional education into the field of school education with a completely different audience and a different level of motivation in educational activities. In addition, the digital educational environment, which includes DER and video content integrated into the originally digital learning management system, does not correspond to the traditional educational environment that uses elements of online learning design. In the previous period of mass computerization of schools, there was no simultaneous process of informatization of education, and, accordingly, the results of education do not meet the needs of its customers. Moreover, there is no convincing evidence that the active informatization of school education leads to a qualitatively significant increase in learning outcomes.

One of the main obstacles for the DET at present is the existing "digital divide". Originally formulated in 2016 by the US Department of Education, the term "digital divide" or "digital inequality" in the use of digital technologies entails the need not only to provide adequate access to technology, but also effective access to expertise on how best to use these technologies, especially to promote interactivity in learning and teaching [16]. Minimizing the disparity in education and social security among children from different backgrounds is a top priority. Several levels of inequality are possible. The first option is the inequality of several children in a family with a single Internet access device, the lack of effective Internet access devices (for example, a laptop or PC), the lack of Internet access, availability of access to the mobile Internet with its high cost and the inability of the family to pay for it. The second option is the level of coordination of the actions of parents and children for the purpose of learning. This is especially significant for primary schools. The willingness of parents to accompany the training, replacing the teacher outside the educational organization (EO) depends not only on the characteristics of their professional activity, but also on their readiness and competence in educational matters. The third option is inequality at the level of the EO itself, both in terms of financing and the possibility of purchasing appropriate equipment and digital educational resources (DER), the quality and quantity of teaching staff across the entire range of subjects. The fourth option is the presence of several generations of people living together in the family. In the context of the COVID-19 pandemic, the maximum separation of generations is necessary, which depends, first of all, on the material security of the family and the characteristics of the traditional way of life. In modern conditions, it is often underage children who are the source of infection of adults and, possibly, the cause of their death.

In the context of an economic downturn, the material well-being of most families deteriorates significantly, which reduces both the educational opportunities of children from these families, and, often, the very possibility of continuing education. In these conditions, the EO needs to develop programs aimed at overcoming digital and economic inequality and 
ensuring the rights of students to quality education, while also maintaining nutrition and medical care programs for children from poor families in a remote form of education [17].

Changes in the usual way of life in the absence of practical skills of self-education and assessment of the reality and quality of their distance learning increases the vulnerability of students to any manifestations of disinformation and influences development of neuropsychiatric symptoms in the form of tantrums, aggression, bedwetting in children, contributes to the transition to the use of psychoactive substances among adolescents and, eventually, to the formation of psychological and mental disorders, chronic stress and posttraumatic stress disorder $[18,19]$. Any negative experience of a student in distance learning does not receive an adequate assessment and without being fixed, forms not only a negative attitude to the education itself, but also transfers it to the student himself, affecting his selfesteem.

In the case of a single-parent family, the risk increases, since only one parent is involved in the rehabilitation of a teenager, and if he cannot work remotely, then no one is involved.

Students with disabilities are in worse conditions, since the cost of specialized digital devices for Internet access is much higher than that of standard ones and usually rare families are able to provide their children with them. Additionally, DER special in content and forms of presentation are extremely rare, for example, those for children with impaired hearing or vision. For them, in the context of distance learning, the inclusive component in modern conditions is simply absent [20].

A number of authors note that during the period of self-isolation, students are much more likely to publish their various photos and personal information. According to the US Department of Justice, one in seven American youth has experienced sexual harassment online; $76 \%$ of cases took place in online chats. $93 \%$ ended up having sex as a result of such conversations. The most often are requests for nude photos, offers to provide sexually explicit information, requests for specific sexual information, and other violations. This is more typical for an audience of 16-17 years old [21].

The use of social networks in students ' leisure time also increases during the period of self-isolation. But when implementing distance learning with the use of technical means, the time of student's contact with gadgets is already significantly increased. At the same time, in the conditions of self-isolation, interpersonal communication of students in an offline format is practically excluded. This inevitably increases the compensatory replacement of such communication by social networks. Reduced physical activity and a sedentary lifestyle also reduce children's satisfaction with life [22]. A number of authors have shown a twofold increase in the influence of increased visual load with limited physical activity on the deterioration of sleep quality and reduced life satisfaction. In fact, the very use of social networks is a risk factor for the health of the user, even without taking into account the psychological and other stress and leads to a deterioration in the perception of personal health and negative health consequences. At the same time, the number of studies on the use of smartphones as devices for monitoring people's social behavior is increasing. The use of smartphones as devices for monitoring people's preferences and behavior provides sufficient information to predict the severity of symptoms of depression, helps to distinguish social anxiety from depression. In the context of the regular collection of such information in the United States today, it can be presented as an inexpensive, low-cost and specific mechanism for identifying people who are vulnerable to problematic levels of social anxiety. The use of special mobile applications and the collection of passive data from participants over a twoweek period continuously (once per second), allows us to obtain significant behavioral signals that significantly exceed the temporal accuracy available in existing measurements of social anxiety, and allows for early diagnosis of maladaptive thoughts and behaviors underlying a wide range of mental states [23]. This phenomenon is considered in the aspect of digital phenotyping using data related to activity, behavior, and communication from 
personal digital devices, such as smartphones and wearable devices [24]. And this approach is used not only in medicine, but also in the assessment and modeling of people's social behavior and predicting the development of depression [25]. Within the framework of education, it helps to predict the development of socialization of students, the main trends in it.

A study by Gallup (USA) in May 2020 shows that $45 \%$ of parents have a very negative view of the isolation of children from their peers, $44 \%$ report a clear decrease in their children's concentration, attention, and motivation [26]. 43\% of working parents say that it is difficult for them to find balance between their work activities and helping with their child's education. $28 \%$ of parents talk about the difficulties of teaching a child outside of the EO, $10 \%$ admit to having technical problems with a computer or Internet access, and $4 \%$ talk about the difficulties of accessing digital educational resources. Young parents with younger children are forced to spend significantly more time to reinforce children's motivation for distance learning (33\%-50\%). In addition, young parents (53\%) who work are more than twice as likely as older parents (24\%) to say that the distribution of time among work, their studies, and their children's studies has been a major problem for their family.

\section{Conclusion}

The COVID-19 pandemic has not only changed the economy of all countries of the world, but also had a significant impact on all social institutions of modern society. Among the leaders of the changes is the education system. At the same time, the existing stratification of society is changing from an economic to a digital paradigm, and it is impossible to overcome it within the framework of only separate education system. But only within this system are the simultaneous digital development of the largest possible group of people students and their parents, their upbringing and development possible. The full social impact of distance learning during the 2020 pandemic can best be understood in retrospect. There is no doubt that the decline in the quality of education will lead to significant difficulties in compensating for it. Now we can talk about a significant aggravation of the inequality of the population in the new area, the area of access to digital technologies and the digital state. Some groups of the population, children, middle-aged people, the elderly, those who do not possess digital skills, have actually been isolated from public life and social communications. The impossibility of online work leads to a significant reduction in income, reduces the social and professional rating of a number of employees. When it was impossible to give up offline work activities, a number of parents were forced to leave their children unattended, because the older age groups were isolated; vertical ties within the families and continuity between the older and younger generations were disrupted.

\section{References}

1. I. Yen-Hao Chu , P. Alam, H.J. Larson, L. Lin, Journal of Travel Medicine, 27(7), taaa192 (2020)

2. S. Tadesse, W. Muluye, Open Journal of Social Sciences, 8, 159 (2020)

3. A.-P. Correia, C. Liu, F. Xu, Distance Education, 1 (2020)

4. Coronavirus pandemic in the EU - Fundamental Rights Implications, 6 (2020) https://fra.europa.eu/

5. Global Education Coalition Gender Flagship: Highlights of action in 2020, https://unesdoc.unesco.org/ 
6. What have we learnt? Overview of findings from a survey of ministries of education on national responses to COVID-19, https://unesdoc.unesco.org/

7. M. Kuhfeld, B. Tarasawa, F. Johnson, E. Ruzek, K. Lewis, Learning during COVID19: Initial findings on students' reading and math achievement and growth (2020) https://www.nwea.org/

8. Education and COVID-19: Focusing on the long-term impact of school closures- OECD (2020) https://read.oecd-ilibrary.org/

9. L.R. Amir, I. Tanti, D.A. Maharani, BMC Med Educ 20, 392 (2020)

10. PISA 2021, Adjusted Design (2021) https://www.oecd.org/

11. C.-L. Tsai, M.-H. Cho, R. Marra, D. Shen, Distance Education, 1 (2020)

12. H. Knott, Distance Education, 41(4), 600 (2020)

13. P. Lowenthal, J. Dunlap, Distance Education, 41(4), 490 (2020)

14. O. M. Albakri, A. Albakri, Exploring the Impact of Digital Learning Platforms on Distance Learning Amidst the COVID-19 Pandemic: A Case of Higher Education Institutions. Fostering Communication and Learning with Underutilized Technologies in Higher Education, 150 (2021)

15. Europian Comission, Digital Education Action Plan (2021-2027) https://ec.europa.eu/

16. U.S. Department of Education Releases 2016 National Education Technology Plan, https://www.ed.gov/

17. Wim Van Lancker, Zachary Parolin, The Lancet Public Health, 5(5), e243 (2020)

18. D. Masha'al, M. Rababa, G. Shahrour, J Nurs Educ., 59(12), 666 (2020)

19. S. Galea, R.M. Merchant, N. Lurie, JAMA Intern Med, 180(6), 817 (2020)

20. M. Kuhfeld, B. Tarasawa, The COVID-19 slide: What summer learning loss can tell us about the potential impact of school closures on student academic achievement (2020) https://www.nwea.org/

21. C. Halupa, RISKS: The impact of online learning and technology on student physical, mental, emotional, and social health, 6305 (2016)

22. G. Buda, J. Lukoševičiūtè, L. Šalčiūnaitè, K. Šmigelskas, Possible Effects of Social Media Use on Adolescent Health Behaviors and Perceptions, Psychological Reports (2020)

23. N. Jacobson, B. Summers, S Wilhelm., Digital Biomarkers of Social Anxiety Severity: Digital Phenotyping Using Passive Smartphone Sensors (2019)

24. P. Jayakumar, E. Lin, V. Galea, A. J. Mathew, N. Panda, I. Vetter, A. B. Haynes, Journal of Personalized Medicine, 10(4), 282 (2020)

25. Nicholas C. Jacobson, Yeon Joo Chung, Sensors, 20(12), 3572 (2020)

26. J. Jones, Social Factors Most Challenging in COVID-19 Distance Learning. Gallup Panel, May 11-24 (2020) https://news.gallup.com/ 